\title{
Textos
}

ANGELA DAVIS / NANCY FRASER / LINDA ALCOFF / CINZIA ARRUZZA / TITHI BHATTACHARYA / ROSA CLEMENTE / Z TAYLOR

\section{Un feminismo para el $99 \%$. Por eso las mujeres haremos huelga este año ${ }^{1}$}

\author{
We Need a Feminism For The 99\%. \\ That's Why Women Will Strike this Year
}

El 8 de marzo haremos huelga contra la violencia machista, contra los hombres que cometen actos de violencia y contra el sistema que los protege.

El 8 de marzo del año pasado, las mujeres de todo tipo marchamos, dejamos de trabajar y tomamos las calles en cincuenta países del mundo. En los Estados Unidos, nos unimos, marchamos, dejamos los platos a los hombres, en todas las grandes ciudades del país y en innumerables más pequeñas. Cerramos tres distritos escolares para demostrarle al mundo, una vez más, que mientras nosotras sostenemos la sociedad, tenemos también el poder de dejar de hacerlo.

El 8 de marzo vuelve y las cosas empeoraron para nosotras en este país.

En un año de la administración Trump, no solo fuimos atacadas con violencia verbal y amenazas misóginas bajo la apariencia de declaraciones oficiales: el régimen de Trump puso en marcha políticas que van a hacer que esos ataques continúen contra nosotras a través de las vías institucionales.

La Ley de Recorte de Impuestos y Empleos les quita los beneficios a lxs trabajadorxs de bajos salarios, de los cuales la gran mayoría son mujeres. Planea atacar con salvajismo a Medicaid y Medicare, los únicos dos programas de salud que quedan en este cruel paisaje neoliberal, para ancianxs y pobres, enfermxs y discapacitadxs, planificación familiar y niñxs y, por lo tanto para las mujeres, que hacen la mayor parte del trabajo de cuidado. Y mientras la ley le niega atención médica a lxs niñxs migrantes, introduce un fondo de ahorro universitario para los «niñxs por nacer», una manera escalofriante de establecer por una vía legal los «derechos» del/a «niñx por nacer» atacando así nuestro derecho fundamental a tomar decisiones sobre nuestros propios cuerpos.

1 Artículo original publicado en inglés en The Guardian el 27 de enero de 2018 (disponible en https: / / www.theguardian.com/commentisfree/2018/jan/27/we-need-a-feminism-for-the-99-thats-whywomen-will-strike-this-year). Ofrecemos la traducción ofrecida por el periódico Latfem (disponible en http://latfem.org/necesitamos-un-feminismo-para-el-99-por-eso-las-mujeres-haremos-huelgaeste-ano/. 
Pero esa no es toda la historia.

Con estos múltiples frentes de batalla abiertos contra nosotras, no nos hemos acobardado. Nosotras también hemos luchado.

Cuando durante el otoño pasado las mujeres con visibilidad pública y acceso a los medios internacionales decidieron romper el silencio sobre el acoso y la violencia sexual, las compuertas finalmente se abrieron y una corriente de denuncias públicas inundó la red. Las campañas \#MeToo, \#UsToo y \#TimesUp visibilizaron lo que la mayoría de las mujeres ya sabían: ya sea en el trabajo o en la casa, en las calles o en el campo, en las cárceles o en los centros de detención para migrantes, la violencia machista, con su particular impacto racista, acecha la vida cotidiana de las mujeres.

Lo que también quedó claro es que el silencio público sobre lo que siempre hemos conocido, soportado y contra lo que hemos luchado, no existe simplemente porque tenemos miedo o vergüenza de hablar: el silencio se impone. Lo imponen las leyes del Congreso, que hacen que las mujeres deban pasar casi un año de consejería obligatoria y mediación, si se atreven a presentar una denuncia. El silencio está influido por un sistema de justicia penal que rechaza como rutina los relatos de las mujeres usando niveles suplementarios de intimidación y violencia. En los campus universitarios, administradores bien dispuestos saben encontrar vías «legales» para proteger a la institución y al agresor, mientras arrojan a las mujeres a los lobos. Los fundamentos racistas de estos procedimientos legales exigen compromisos de fondo.

\#Metoo, \#UsToo y \#TimesUp no solo han expuesto a los violadores y misóginos, sino que hicieron un tajo en el velo que oculta a las instituciones y las estructuras que les habilitan esa conducta.

La violencia machista de corte racial es internacional, como debe ser la campaña en su contra. El imperialismo estadounidense, el militarismo y el colonialismo fomentan la misoginia en todo el mundo. No es coincidencia que Harvey Weinstein, en sus largos años de tratar de silenciar y aterrorizar a las mujeres, usara la empresa de seguridad Black Cube, formada por ex agentes del Mossad y otras agencias de inteligencia israelíes. Sabemos que el mismo Estado que envía dinero a Israel para tratar con brutalidad a la palestina Ahed Tamimi y su familia, también financia las cárceles en las que mujeres afroamericanas como Sandra Bland y otras han muerto.

Entonces, el 8 de marzo haremos huelga contra la violencia machista, contra los varones que cometen actos de violencia y contra el sistema que los protege.

Creemos que no fue accidental que nuestras hermanas con posición social fueran las que primero hicieron visible lo que todos sabíamos. Sus posibilidades de hacerlo visible eran más grandes que las de nuestras hermanas de bajos ingresos, a menudo de color, que limpian habitaciones en ese lindo hotel de Chicago o las de las hermanas que recogen frutas en los campos californianos.

La gran mayoría de nosotras no hablamos porque no tenemos un poder colectivo en nuestros lugares de trabajo y se nos niega cobertura social, como la atención médica gratuita, fuera de ellos. El trabajo, con su salario bajo, con su gerente intimidante y su jefe abusivo, con sus largas horas, se convierte en lo único que tenemos miedo de perder, ya que es el único medio para llevar los alimentos a 
nuestras familias y poder cuidar a nuestros enfermxs.

No mantenemos nuestra boca cerrada. Nos vemos obligadas a mantener la boca cerrada por el capitalismo.

Entonces, el 8 de marzo hablaremos, individualmente, contra los abusadores que trataron de arruinar nuestras vidas, y hablaremos colectivamente contra la inseguridad económica que nos quiere impedir hablar.

Vamos a parar porque queremos exponer a nuestros abusadores. $\mathrm{Y}$ haremos huelga porque necesitamos seguridad social y trabajos que tengan salarios dignos para poder alimentar a nuestras familias, del mismo modo que derecho a sindicarnos, en caso de que nos despidan por defendernos del abuso.

Entonces, el 8 de marzo haremos huelga por el encarcelamiento masivo, la violencia policial y los controles fronterizos, contra la supremacía blanca y las guerras imperialistas estadounidenses, contra la pobreza y la violencia estructural en nuestras escuelas y hospitales, que envenena nuestras aguas y alimentos y nos niega una justicia reproductiva.

Y vamos a parar por los derechos laborales, la igualdad de derechos para todxs lxs migrantes, por un salario digno y equitativo, porque la violencia sexual en el lugar de trabajo puede agravarse cuando no tenemos una protección colectiva.

El 8 de marzo de 2018 será un día de feminismo para el 99\%: un día de movilización de las mujeres negras y morenas, de las cis y bi, de las lesbianas y las mujeres trans, de las pobres y las de bajos salarios, de las que hacen trabajos de cuidado no remunerados, de las trabajadoras sexuales y de las migrantes.

El 8 de marzo \#NosotrasParamos.

Linda Alcoff, Cinzia Arruzza, Tithi Bhattacharya, Rosa Clemente, Angela Davis, Zillah Eisenstein, Liza Featherstone, Nancy Fraser, Barbara Smith y Keeanga-Yamahtta Taylor. 